\title{
THE EFFLUX OF BLOOD FROM THE CAROTID ARTERY OF THE DOG AND ITS EXPRESSION BY A GENERAL EMPIRICAL FORMULA *
}

\author{
HALBERT L. DUNN, B.A., M.A. \\ MINNEAPOLIS
}

The study of the normal and pathologic significance of the blood pressure has been a subject of interest for many years. It was not until mechanical instruments were available, however, that any accurate measurements of blood pressure were taken. Ludwig, in 1847, first obtained a blood pressure tracing. In 1882, almost forty years later, $\mathrm{V}$. Basch invented the tonometer. Roy and Adami in 1890 modified this for external use and Riva Rocca in 1896 manufactured the first practical clinical instrument for taking blood pressures.

During the last two decades, the clinical literature has been filled with blood pressure observations on both man and animal. The normal blood pressure of man has been established by a score of investigators; Alvarez, ${ }^{1}$ Barach and Marks, ${ }^{2}$ Cook, ${ }^{3}$ Dawson,, ${ }^{4}$ Fisher, ${ }^{5}$ Frau Wolfensohn-Kriss, ${ }^{6}$ Goepp, ${ }^{7}$ Greene, ${ }^{8}$ Kammerer, ${ }^{9}$ Lee, ${ }^{10}$ MacKenzie, ${ }^{11}$ Michael, ${ }^{12}$ Sallom,${ }^{13}$ Smith, ${ }^{14}$ Sorapure, ${ }^{11}$ Weysse, ${ }^{16}$ and Woley. ${ }^{1 i}$ The

* From the Physiology Department, University of Minnesota.

1. Alvarez, W. C.: Blood Pressure in University Freshmen, Arch. Int. Med, $26: 381$ (Sept.) 1920.

2. Barach, J. H.: Blood Pressures, Arch. Int. Med. 13:648 (May) 1914

3. Cook, H. W.: Clinical Value of Blood Pressure Determinations as a Guide to Stimulation in Sick Children, Am. J. M. Sc. 125:483, 1903.

4. Dawson: Physical Training Effect on Pulse and Blood Pressure, Am. J. Phys. 42:590, 1917.

5. Fisher: Blood Pressure, Proc. Ass. Life Ins. Med. Directors of America, 1915 , pp. 90,246 ; 1917, p. 203.

6. Frau Wolfensohn-Kriss, P.: Ueber den Blutdruck in Kindesalter, Arch. f. Kinderh. 52-53:332, 1910.

7. Goepp, R. M.: Blood Pressure as a Prognostic Factor, Penn. M. J. 22: 295 (Feb.) 1919.

8. Greene, R. N.: Aviation and Blood Pressure, Lancet 1:63, 1918.

9. Kammerer: Blood Pressure in the Trenches, München. med. Wchnschr. 64: 849,1917

10. Lee, R. I.: Blood Pressure Determinations, Urinary Findings and Differential Blood Counts in a Group of 662 Young Male Adults, Boston M. \& S. J. $173: 541,1915$.

11. Mackenzie: Blood Pressure, Proc. Assn. Life Ins. Med. Directors of America, N. Y., 1917, p. 221.

12. Michael, M.: A Study of Normal Blood Pressure in Children, Am. J. Dis. Child. 1:272 (March) 1911.

13. Sallom, A. K.: Standardization of Blood Pressure, New York M. J. 92:620 (Sept. 24) 1910.

14. Smith, B.: Blood Pressure Studies of 500 Men, J. A. M. A. 71:171 (July 20) 1918.

15. Sorapure, V. E.: Blood Pressure and Physical Fitness of the Soldier, Lancet 2:841 (Dec. 21) 1918.

16. Weysse: Diurnal Variation in Arterial Blood Pressure, Am. J. Physiol. 37: 330,1915 .

17. Woley, H. G.: The Normal Variation of the Systolic Blood Pressure, J. A. M. A. 55:121 (July 9) 1910. 
series by Goepp included 9,996 determinations; that of Fisher, 12,647; and that of MacKenzie, 31,934. A recognized normal blood pressure has been established also by several large insurance companies. The Northwestern National Life Insurance Company, for instance, uses an average scale ranging between 120 systolic pressure at 20 years to 136 systolic at 60 years. Much has been done to correlate high blood pressures with certain diseases, for instance, the toxemias of pregnancy, hypertension and arteriosclerosis.

Although blood pressure has been studied extensively, no attempt has been made to establish a correlation between it and blood flow. The present work is an effort to secure such a correlation. By means of quantitative methods and the graphic analysis of the results, a relationship between the arterial blood pressure and the efflux of blood from a cannula of known size was obtained. The data of this work are entirely from dog experiments. Ary application of this relationship to direct arteriovenous transfusion can be used only after further observations on human material are made. This work was done under the physiology department at the Cniversity of Minnesota and material assistance was rendered by Dr. F. H. Scott and Dr. R. E. Scammon. Credit is also due to Mr. J. F. Borg and Mr. H. R. Smithies, who assisted in some of the experiments.

In addition to obtaining the relationship of blood pressure to blood flow, the total blood volume of each dog was determined. These data are reserved for a later publication.

\section{MATERIAL}

The dog was selected as the best laboratory animal to be used for the experiment. Eighteen dogs were used, differing in sex, variety, and size. No distinction was made between sex and variety since these factors did not bear on the problem. The size of the animal was important, however, since it was necessary for the carotid artery of the dog to be larger than the lumen of the cannula used for the experiment. The dogs were all in good health and had not been used for previous experimentation of any kind. The cannules used for the problem were manufactured by the Wilson and Wilson Company, Boston. These cannules are made from the same material as are their nickle plated steel needles and they correspond to them in gage size. The ends of the cannules are made blunt, however, to eliminate experimental error.

\section{METHCDS}

A uniform technic was employed for all of the experiments. From twenty to thirty beakers were prepared for the collection of the blood of the animal. Into each of these $5 \mathrm{c}$. c. of sodium citrate solution were 
measured by means of a buret. A bulb, T-shaped cannula was inserted into the left carotid artery and one arm connected to a mercury manometer for recording arterial blood pressure.

The internal surface of the metal cannula was coated with liquid petrolatum to prevent the formation of a blood clot. All but a thin film of the petrolatum was washed out by hot water. A rubber tube was fastened to the cannula in order to convey the blood from the carotid artery to the beakers. This tube was filled with a solution of physiologic sodium chlorid solution so that the blood flow for the first ten seconds would not be inaccurate. After finishing all the preliminary preparations the last thing done before starting the experiment was to insert this cannula in the right carotid artery. The kymograph was started and a normal curve of blood pressure was taken. Then the clip was removed from the right carotid and the blood was permitted to flow through the cannula. At the end of each ten seconds the blood flow was deviated to another beaker and the time was indicated on the kymograph tracing. When the animal ceased to bleed the arteries were cut and all of the blood was drained from them. No attempt was made to perfuse the animal. The amount of blood in each beaker was accurately measured to $0.5 \mathrm{c}$. c. The mean blood pressure for the respective intervals of ten seconds was obtained from the tracings. The determinations for all the data necessary in the experiment were now complete, except for the estimation of the area of the cannula lumen. The diameter of the lumen of the cannula was measured by means of a vernier caliper, accurate to one hundredth millimeter. The cross section area of the lumen was calculated by using the formula for the area of a circle: Area $=3.1416\left(\mathrm{r}^{2}\right)$ in which $r$ is the radius in $\mathrm{mm}$.

\section{ACCURACY OF THE DATA}

It is essential to estimate the accuracy of the data in order to obtain a relationship between the three variables, blood pressure, blood flow and the size of the lumen of a cannula. The cross section area of the lumen of the cannula can be determined with considerable exactness. All the cannules were measured in the same manner. The diameter of each was obtained by averaging thirty readings of the vernier caliper. By this means an accurate determination of the cross section area of the cannula was obtained. The blood flow per ten seconds is also an accurate measurement since it is not distorted in any way by experimental error. The blood pressure, however, is not as exact an observation. The necessity for an absolutely accurate baseline was not obvious while the experiments were being carried out. The error in its determination occurred because the third arm of the three way cannula was not kept horizontal to the carotid artery. The variation ranged from 2 to $10 \mathrm{~mm}$. $\mathrm{Hg}$. 
TREATMENT OF THE DATA

The accuracy of the data is very important for the successful interpretation of the physiologic relationship between the blood pressure and the blood flow. The significance of the results, however, can be obtained only by an application of graphic and mathematical analysis to the data. The methods used in this series of experiments are three in number: (1) the construction of field graphs and drawing curves by inspection; (2) the determination of a general empirical formula, and (3) the comparison of the inspected absolute curves to the respective curves derived by the general empirical formula.

1. The construction of field graphs, together with the establishment of curves showing the central tendency of the data, was the first method of graphic analysis which was attempted. Each graph (Figs. 1, 2, 3, 4,5 and 6) includes the data which were obtained by the use of a certain cannula. In each figure the abscissa represents blood flow in c. c. per ten seconds, while the ordinate is the blood pressure of the animal in mm. of $\mathrm{Hg}$. The curve drawn by inspection does not signify a curve of mathematical accuracy but merely represents the best expression of the judgment of the author as to the central tendency of the data.

Figure 8 is also a field graph. In this instance the abscissa represents the area of the lumen of the cannula. The ordinate shows the average blood flow per ten second interval for the respective cannules.

2. After the field graphs were made and the inspected curves were drawn for each, a general formula was calculated expressing the blood flow in terms of the blood pressure and the cross section area of the cannula. This general formula was obtained by the method of trial and error. In determining the equation, the values of the cross section area of the cannula were kept unchanged. Blood pressure values were also kept as nearly similar to the respective observed determinations as the nature of the data would permit. The best general formula can be expressed as follows: Blood flow (c. c.) $=0.17$ (area [sq. $\mathrm{mm}$.]) (Blood pressure [mm. $\mathrm{Hg}$.$] ) in which blood flow is the efflux$ of blood from a cannula per ten seconds of time, area is the cross section area of the lumen of the cannula in sq. mm., blood pressure is the average blood pressure in $\mathrm{mm}$. of $\mathrm{Hg}$., and the number 0.17 is an empirically determined constant.

3. The comparison of the absolute values of the curves drawn by inspection with the corresponding determinations of the general formula is demonstrated graphically and numerically. On each absolute graph (Figs. 1, 2, 3, 4, 5 and 6) both the inspected and the calculated curve are inserted, the former by a solid line and the latter by a broken line. 


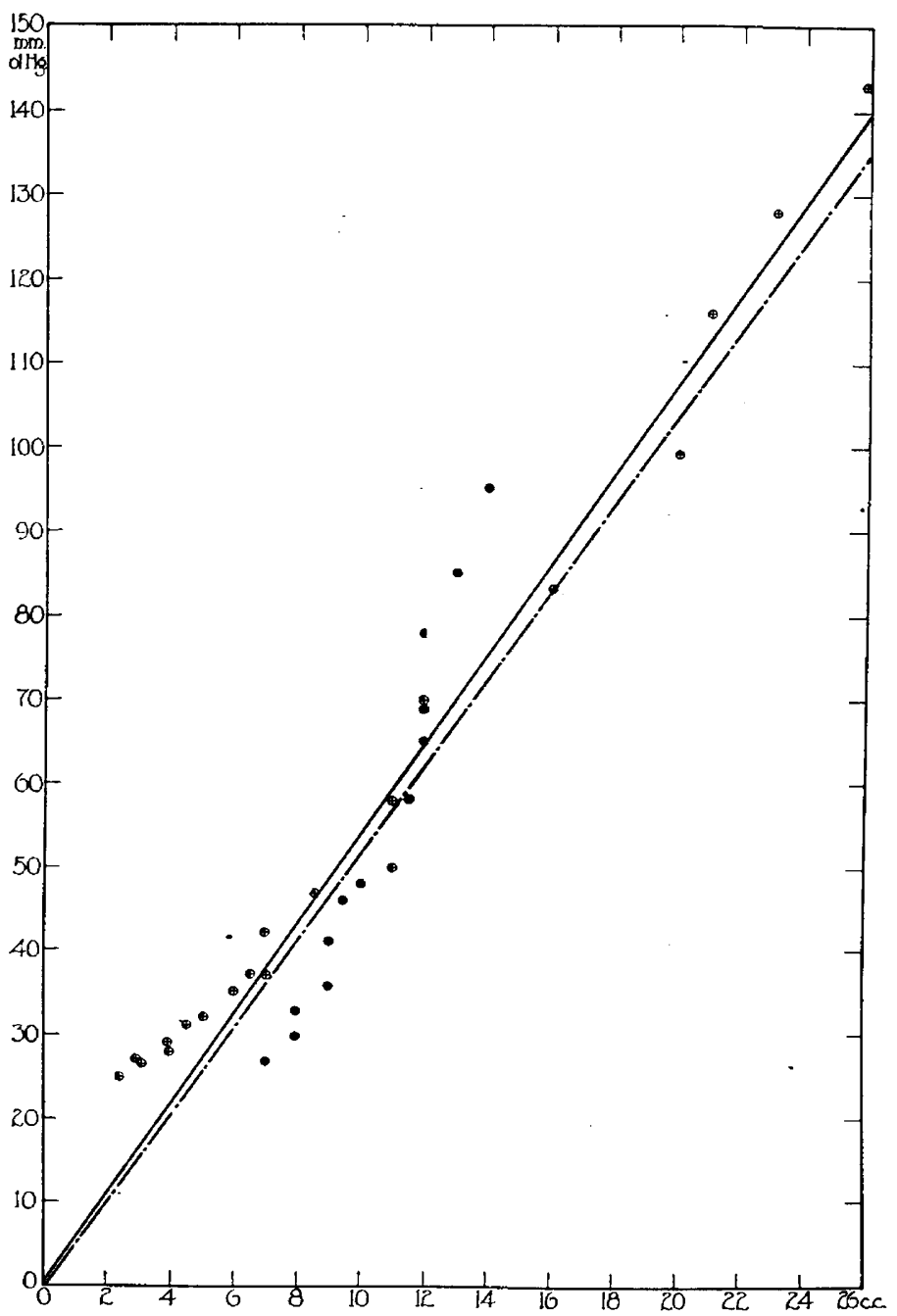

Fig. 1.-A field graph and curves expressing the relationship between blood flow and blood pressure. A cannula was used which had outlet $1.131 \mathrm{sq} . \mathrm{mm}$. in area. Abscissa: efflux of blood in cubic centimeters per 10 seconds of time. Ordinate: blood pressure in millimeters of $\mathrm{Hg}$. Individual cases are indicated by solid dots (for Experiment 1) and by circle-crosses (for Experiment 2). The solid line represents a curve drawn by inspection. The broken line is a curve drawn to the general empirical formula: Blood flow (c.c.) $=0.17$ (area [sq. mm.]) (blood pressure [mm. Hg.]). 


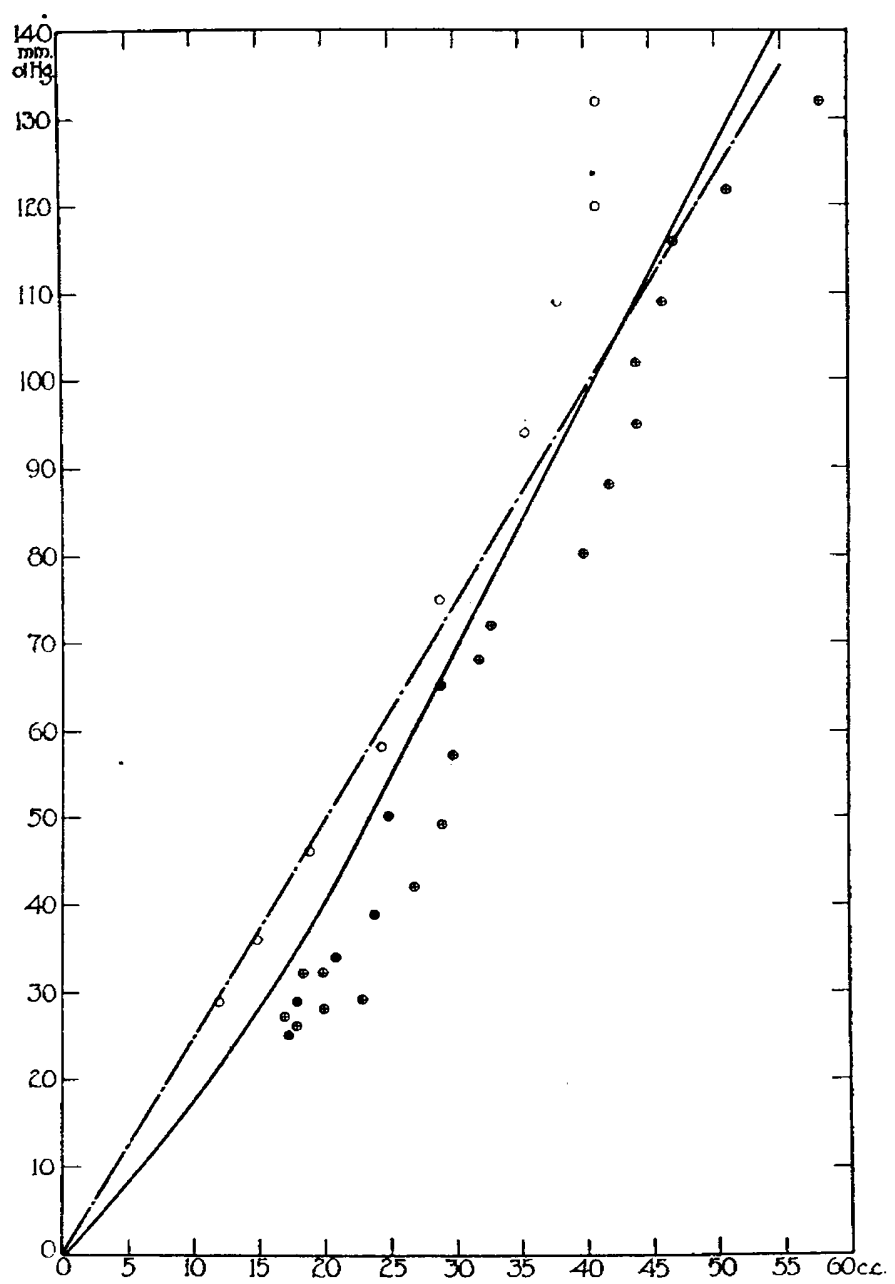

Fig. 2.-A field graph and curves expressing the relationship between blood flow and blood pressure. A cannula was used which had an outlet 2.378 sq. $\mathrm{mm}$. in area. Abscissa: efflux of blood in c. c. per 10 seconds of time. Ordinate: blood pressure in $\mathrm{mm}$. $\mathrm{Hg}$. Individual cases are indicated by solid dots (for Experiment 3), by circle-crosses (for Experiment 4) and by open circles (for Experiment 5). The solid line represents a curve drawn by inspection. The broken line is a curve drawn to the general empirical formula: Blood flow (c.c.) $=0.17$ (area [sq. mm.]) (blood pressure [mm. Hg.1). 
In Figure 7 these curves are grouped to a uniform scale. The curves drawn by inspection are paired with those which were calculated and the corresponding pairs numbered according to the respective graphs.

The numerical comparison of the respective values which are taken from the curves drawn by inspection and those calculated by the general empirical formula is seen in Tables 1 and 2 .

Table 1 contrasts in parallel columns the observed and the calculated values of both the average blood flow and the average blood pressure for each experiment.

Table 2 shows the observed and the theoretical values of the average blood flow and the average blood pressure for each graph.

\section{EXPERIMENTAL OBSERVATIONS}

A summary of the observations made on the data is divided for convenience into four subdivisions: (1) a consideration of the absolute data which are presented by means of field graphs and tables; (2) an enumeration of averages obtained from this absolute data; (3) a comparison of the observed and calculated values, and (4) the significance of the relationship between the blood flow and the size of the cannula outlet.

1. The absolute data available for this study are set forth in the field graphs (Figs. 1, 2, 3, 4, 5 and 6) and in Table 1.

Figure 1 is a field graph based on two experiments. Each of the dogs selected weighed $4.54 \mathrm{~kg}$. The cannula used was gage 16 and had an opening $1.131 \mathrm{sq}$. $\mathrm{mm}$. in area. The curve, drawn by inspection, shows that 26 c. c. of blood flows from the cannula in ten seconds when the blood pressure is. $140 \mathrm{~mm}$. of $\mathrm{Hg}$. This amount of blood outflow steadily decreases until at $25 \mathrm{~mm}$. of arterial pressure only 3 c. c. of blood flows from the cannula per ten seconds of time. The curve indicated by dashes is the general empirical formula: Blood flow (c. c.) $=0.17$ (area [sq. mm.]) (Blood pressure [mm. $\mathrm{Hg}$.$] ). It is$ slightly lower than the curve drawn by inspection.

Figure 2 is a field graph based on three experiments, the dogs weighing $5.67,13.4$ and $7.72 \mathrm{~kg}$, respectively. The cannula used in these experiments was gage 14 in size and had a cross section area of $2.378 \mathrm{sq} . \mathrm{mm}$. The curve drawn by inspection shows that $55 \mathrm{c}$. c. of blood leave the cannula in ten seconds when the blood pressure is 140 $\mathrm{mm}$. of $\mathrm{Hg}$. The arterial pressure descends rapidly to $40 \mathrm{~mm}$, at which point the efflux of blood in ten seconds is $20 \mathrm{c}$. c. The curve drawn by calculation from the general formula is a straight line which falls slightly below the inspected curve at a blood pressure above $100 \mathrm{~mm}$. of $\mathrm{Hg}$. and slightly above the inspected curve at an arterial pressure below $100 \mathrm{~mm}$. of $\mathrm{Hg}$. 


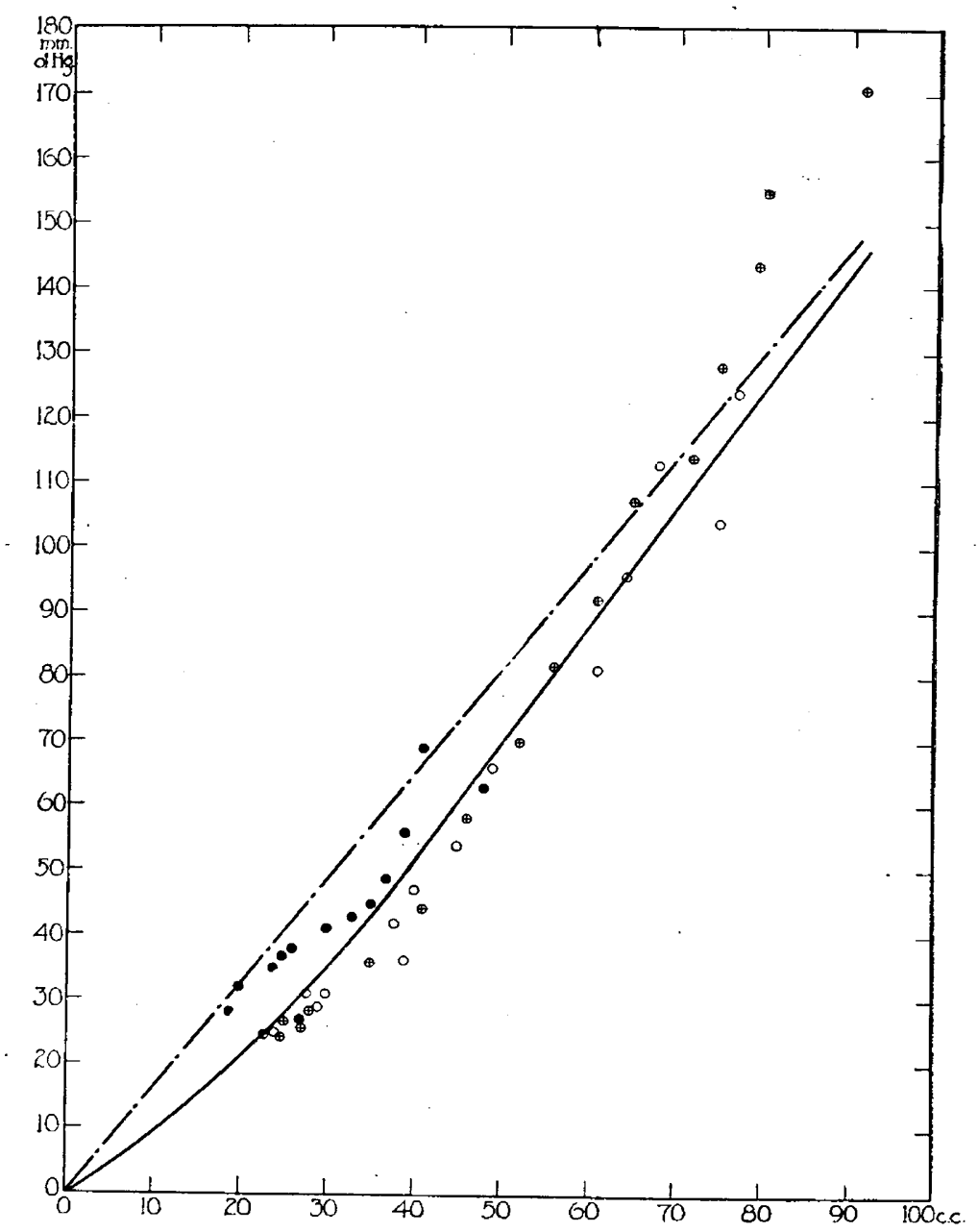

Fig. 3.-A field graph and curves expressing the relationship between blood flow and blood pressure. A cannula was used 'which had an outlet 3.597 sq. $\mathrm{mm}$. in area. Abscissa : efflux of blood in c.c. per 10 seconds of time. Ordinate: blood pressure in $\mathrm{mm}$. of $\mathrm{Hg}$. Individual cases are indicated by solid dots (for Experiment 6), by circle-crosses (for Experiment 7) and by open circles (for Experiment 8). The solid line represents a curve drawn by inspection. The broken line is a curve drawn to the general empirical formula: Blood flow (c.c.) $=0.17$ (area [sq. mm.]) (blood pressure [mm. Hg.]). 


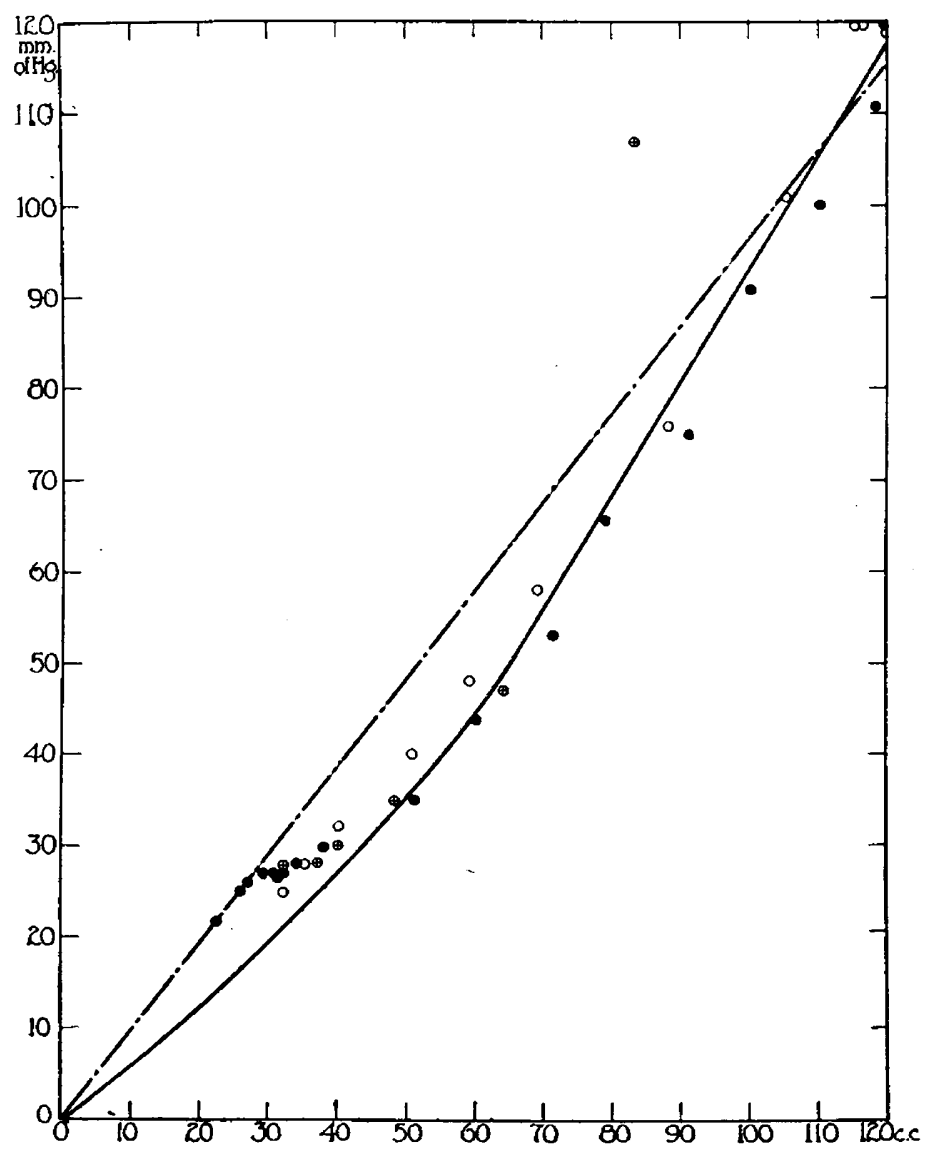

Fig. 4.-A field graph and curves expressing the relationship between blood flow and blood pressure. A cannula was used which had an outlet $5.2 \mathrm{sq} . \mathrm{mm}$. in area. Abscissa: efflux of blood in c.c. per 10 seconds of time. Ordinate: blood pressure in $\mathrm{mm}$. of $\mathrm{Hg}$. Individual cases are indicated by solid dots (for Experiment 9), by circle-crosses (for Experiment 10) and by open circles (for Experiment 11). The solid line represents a curve drawn by inspection. The broken line is a curve drawn to the general empirical formula: Blood flow (c.c.) $=0.17$ (area [sq. mm.]) (blood pressure [mm. $\mathrm{Hg}$.$] ).$ 
Figure 3 expresses the absolute relationship between blood pressure and blood outflow per interval of time when the cannula has a cross section area of $3.597 \mathrm{sq}$. $\mathrm{mm}$. Three experiments were carried out to establish this relationship, the dogs weighing 9.54, 20.45 and 15.2 kg., respectively. The blood pressure decreases more rapidly in amount than does the blood flow per unit of time. At $127 \mathrm{~mm}$. of arterial pressure there is approximately $80 \mathrm{c}$. c. of blood flow from the carotid in ten seconds. The blood pressure decreases rapidly to $25 \mathrm{~mm}$. and the blood flow to 23 c. c. per ten seconds. The calculated curve is at all times higher than the curve drawn by inspection.

The absolute data set forth in Figure 4 varies more widely from the empirical formula than do those of any other field graph. Three dogs, weighing $28.1,10.13$ and $21.8 \mathrm{~kg}$., respectively, were used to establish this relationship. The cross section area of the cannula was 6.07 sq. $\mathrm{mm}$. The inspected curve is distinctly concave descending rapidly from a blood pressure of $118 \mathrm{~mm}$. of $\mathrm{Hg}$. and a blood outflow of 120 c. c. per ten seconds of time to a blood pressure of $50 \mathrm{~mm}$. of $\mathrm{Hg}$. and a blood outflow of $68 \mathrm{c}$. c. per ten seconds. The descent is then more slow until the efflux of blood per ten seconds of time reaches 37 c. c. at $25 \mathrm{~mm}$. of arterial pressure. The curve of the general empirical formula is definitely higher than the inspected curve although it is approximately correct for the higher blood pressures.

Figure 5 shows the relationship of blood pressure to the efflux of blood when a cannula with an outlet area of $7.548 \mathrm{sq} . \mathrm{mm}$. was employed. Four dogs weighing 12.3, 22.7, 20.4 and $27.3 \mathrm{~kg}$., respectively, were used. The individual cases are scattered in this figure although the central tendency is quite obvious and is expressed by the curve drawn by inspection. This curve shows that 220 c. c. of blood leave the cannula in ten seconds of time when the blood pressure is $159 \mathrm{~mm}$. of $\mathrm{Hg}$. The curve descends steadily to $37 \mathrm{c}$. c. of blood outflow at $25 \mathrm{~mm}$. of arterial pressure. The curve drawn by the general empirical formula is slightly higher than that drawn by inspection.

The experiments set forth in Figure 6 were made on three dogs weighing 26.4, 20.0 and $25.1 \mathrm{~kg}$, respectively. 'The cannula used to drain off the blood had a cross section area of 9.512 sq. mm. The central tendency of the individual cases in this figure is expressed by the inspected curve. This curve shows that 200 c. c. of blood flows from the cannula in ten seconds when the arterial pressure is 135 $\mathrm{mm}$. of $\mathrm{Hg}$. and that the amount of blood outflow per ten seconds of time descends steadily to the amount of $35 \mathrm{c}$. c. at a blood pressure of $25 \mathrm{~mm}$. of $\mathrm{Hg}$.

The absolute data for each experiment are summarized in Table 1. The number of observations on each dog and the number of experiments for each figure are given. The body weight of the dog before 


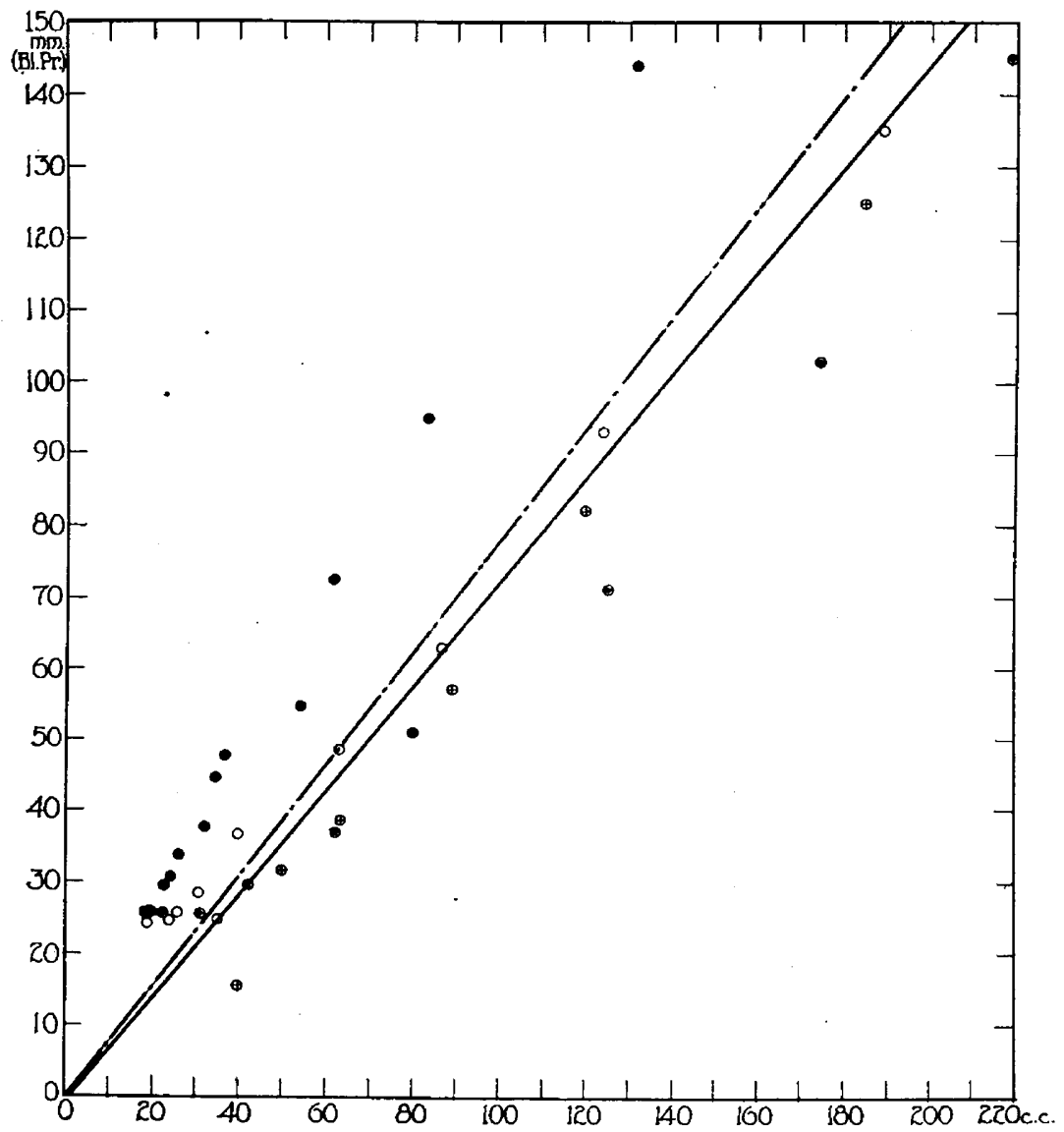

Fig. 5.-A field graph and curves expressing the relationship between blood flow and blood pressure. A cannula was used which had an outlet 7.548 sq. $\mathrm{mm}$. in area. Abscissa: efflux of blood in c.c. per 10 seconds of time. Ordinate: blood pressure in $\mathrm{mm}$. of $\mathrm{Hg}$. Individual cases are indicated by solid dots (for Experiment 12), by circle-crosses (for Experiment 13), by open circles (for Experiment 14) and by circle-dots (for Experiment 15). The solid line represents a curve drawn by inspection. The broken line is a curve drawn to the general empirical formula : Blood flow (c.c.) $=0.17$ (area [sq. $\mathrm{mm}$.]) (blood pressure [mm. $\mathrm{Hg}$.$] ).$ 


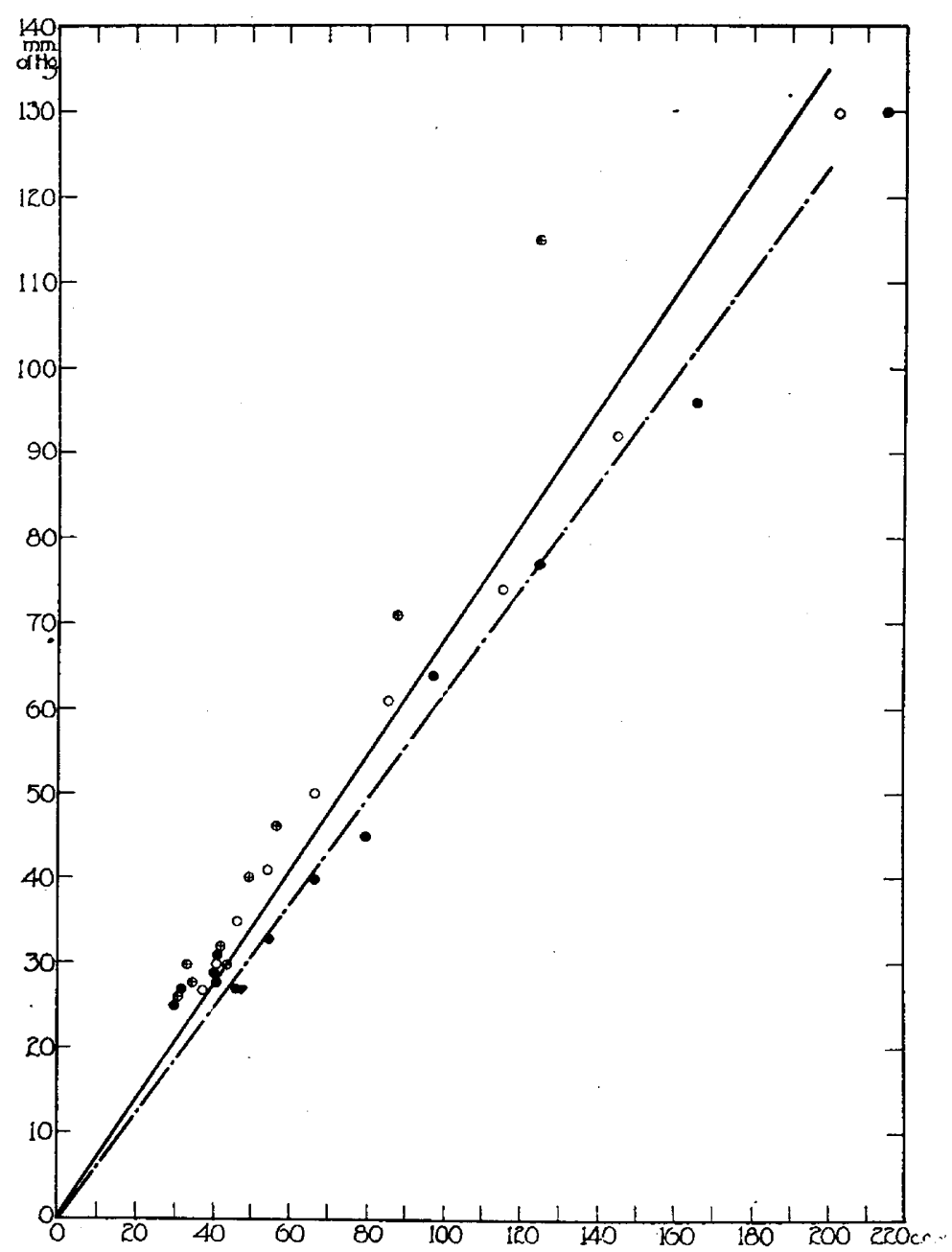

Fig. 6.-A field graph and curves expressing the relationship between blood flow and blood pressure. A cannula was used which had an outlet 9.512 sq. $\mathrm{mm}$. in area. Abscissa : efflux of blood in c.c. per 10 seconds of time. Ordinate: blood pressure in $\mathrm{mm}$. of $\mathrm{Hg}$. Individual cases are indicated by solid dots (for Experiment 16), by circle-crosses (for Experiment 17) and by open circles (for Experiment 18). The solid line represents a curve drawn by inspection. The broken line is a curve drawn to the general empirical formula: Blood flow (c.c.) $=0.17$ (area [sq. $\mathrm{mm}$ ]) (blood pressure $[\mathrm{mm}$. $\mathrm{Hg}$.$] ).$ 
TABle 1.-Absolute Data for Individual Experiments

Blood Volume (C.c.) $=0.17$ (Area [SQ. Mm.]) (Blood Pressure [M M. of HG.])

\begin{tabular}{|c|c|c|c|c|c|c|c|c|}
\hline \multirow[b]{2}{*}{$\begin{array}{c}\text { Number } \\
\text { of } \\
\text { Graph }\end{array}$} & \multirow[b]{2}{*}{$\begin{array}{c}\text { Number } \\
\text { of } \\
\text { Experi- } \\
\text { ment }\end{array}$} & \multirow{2}{*}{$\begin{array}{c}\text { Number } \\
\text { of } \\
\text { Obser- } \\
\text { vations } \\
\text { in } \\
\text { Experi- } \\
\text { ment }\end{array}$} & \multirow[b]{2}{*}{$\begin{array}{c}\text { Weigbt } \\
\text { of } \\
\text { Dog, } \\
\text { Kg. }\end{array}$} & \multirow[b]{2}{*}{$\begin{array}{c}\text { Total } \\
\text { Volume } \\
\text { of } \\
\text { Blood, } \\
\text { C.c. }\end{array}$} & \multicolumn{2}{|c|}{$\begin{array}{l}\text { Average Blood Flow, } \\
\text { O.c. }\end{array}$} & \multicolumn{2}{|c|}{$\begin{array}{c}\text { Average Blood Pressure, } \\
\mathbf{M m} \text {. of } \mathbf{H g}\end{array}$} \\
\hline & & & & & Observed & $\begin{array}{c}\text { Calculated } \\
\text { from } \\
\text { Observed } \\
\text { Average } \\
\text { Blood } \\
\text { Pressure }\end{array}$ & Observed & $\begin{array}{c}\text { Calculated } \\
\text { from } \\
\text { Observed } \\
\text { Average } \\
\text { Blood } \\
\text { Flow }\end{array}$ \\
\hline \multirow{2}{*}{1} & 1 & 13 & 4.54 & 200 & 10.30 & 10.58 & 55.0 & 54.0 \\
\hline & 2 & 20 & 4.54 & 234 & 10.05 & 10.98 & 57.2 & 52.3 \\
\hline \multirow{3}{*}{2} & 3 & 6 & 5.67 & 329 & 22.30 & 16.30 & 40.3 & 55.4 \\
\hline & 4 & 19 & 13.40 & 806 & 33.60 & 27.85 & 69.0 & 83.5 \\
\hline & 5 & 9 & 7.72 & 381 & 28.30 & 31.12 & 77.0 & 70.3 \\
\hline \multirow{3}{*}{3} & 6 & 12 & 9.54 & 488 & 31.40 & 27.35 & 44.7 & 51.4 \\
\hline & 7 & $1 i$ & 20.45 & 1,074 & 52.00 & 47.90 & 78.3 & 84.7 \\
\hline & 8 & 15 & 15.20 & 825 & 46.40 & 36.90 & 60.4 & 75.8 \\
\hline \multirow{3}{*}{4} & 9 & 17 & 28.10 & 1,333 & 61.70 & $55 . \varepsilon 0$ & 54.0 & 59.7 \\
\hline & 10 & 6 & 10.13 & 408 & 50.70 & 47.40 & 45.8 & 49.0 \\
\hline & 11 & 11 & 21.8 & 1,215 & 75.50 & 72.10 & 69.8 & 73.0 \\
\hline \multirow{4}{*}{$\bar{\delta}$} & 12 & 11 & 12.3 & 633 & 48.00 & 71.90 & 56.0 & 36.9 \\
\hline & 13 & 7 & 22.7 & 948 & 83.00 & 69.40 & 54.0 & 64.8 \\
\hline & 14 & 9 & 20.4 & 790 & 67.00 & 68.50 & 53.4 & 52.4 \\
\hline & 15 & 9 & 27.3 & 1,204 & 86.10 & 73.40 & 57.2 & 67.2 \\
\hline \multirow{3}{*}{6} & 16 & 14 & 26.4 & 1,509 & 77.60 & 78.40 & 48.5 & 48.0 \\
\hline & 17 & 9 & 20.2 & 737 & 56.30 & 75.0 & 46.4 & 34.8 \\
\hline & 18 & 9 & 25.1 & 1,206 & 88.30 & 97.0 & 60.0 & 54.6 \\
\hline
\end{tabular}

TABle 2.-Absolute Data for Each Graph

Blood Volume (C.c.) $=0.17$ (Area [Sq. Mm.]) (Blood Pressure [M m. of Hg.])

Blood Pressure (M M. of HG. $=\frac{\text { Blood Volume (C.c.) }}{0.17 \text { Area }\left(\text { SQ. M. }_{\text {. }}\right)}$

\begin{tabular}{|c|c|c|c|c|c|c|c|}
\hline \multirow[b]{2}{*}{$\begin{array}{l}\text { Numbers } \\
\text { of Graphs }\end{array}$} & \multicolumn{3}{|c|}{ Cannula } & \multicolumn{2}{|c|}{$\begin{array}{l}\text { Average Blood Flow, } \\
\text { O.c. }\end{array}$} & \multicolumn{2}{|c|}{$\begin{array}{c}\text { Average Blood Pressure, } \\
\mathbf{M m} \text {. of } \mathbf{H g}\end{array}$} \\
\hline & $\begin{array}{l}\text { Radius } \\
\text { of } \\
\text { Lumen, } \\
\text { Mm. }\end{array}$ & $\begin{array}{c}\text { Area } \\
\text { of } \\
\text { Lumen, } \\
\text { Sq.Mm. }\end{array}$ & $\begin{array}{c}\text { Approxi- } \\
\text { mate } \\
\text { Gage }\end{array}$ & Observed & $\begin{array}{c}\text { Calculated } \\
\text { from } \\
\text { Observed } \\
\text { Average } \\
\text { Blood } \\
\text { Pressure }\end{array}$ & Observed & $\begin{array}{c}\text { Caleulated } \\
\text { from } \\
\text { Observed } \\
\text { Average } \\
\text { Blood } \\
\text { Volume }\end{array}$ \\
\hline $\begin{array}{r}1 \text { and } 2 \\
3 \text { and } 4 \\
5 \text { and } 6 \\
7 \text { and } 8 \\
9 \text { and } 10 \\
11 \text { and } 12\end{array}$ & $\begin{array}{l}0.60 \\
0.87 \\
1.07 \\
1.39 \\
1.55 \\
1.74\end{array}$ & $\begin{array}{l}1.131 \\
2.378 \\
3.597 \\
6.070 \\
7.548 \\
9.512\end{array}$ & $\begin{array}{l}16 \\
14 \\
13 \\
11 \\
- \\
-\end{array}$ & $\begin{array}{l}10.2 \\
30.2 \\
44.4 \\
64.2 \\
69.1 \\
74.6\end{array}$ & $\begin{array}{l}10.8 \\
26.7 \\
38.6 \\
59.5 \\
70.9 \\
82.6\end{array}$ & $\begin{array}{l}56.2 \\
\mathbf{6 6 . 1} \\
63.0 \\
\mathbf{5 7 . 6} \\
55.2 \\
\mathbf{5 1 . 1}\end{array}$ & $\begin{array}{l}53.0 \\
74.7 \\
72.5 \\
62.2 \\
53.7 \\
\mathbf{4 6 . 1}\end{array}$ \\
\hline
\end{tabular}




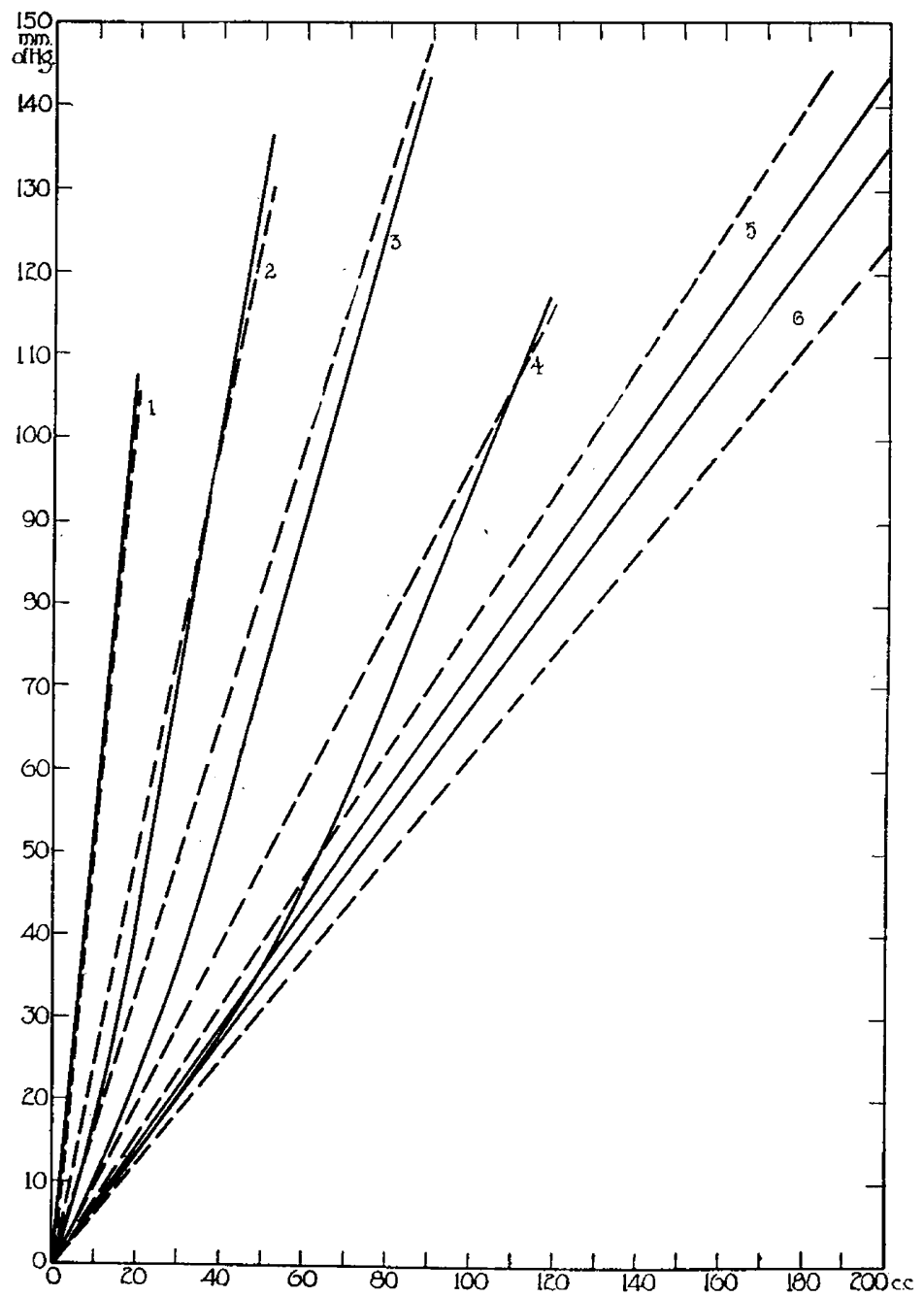

Fig. 7.-A series of curves illustrating the relationship between blood pressure and the efflux of blood per 10 seconds of time. These curves are taken from Figures 1, 2, 3, 4, 5 and 6. Abscissa: Blood flow in c.c. per 10 seconds. Ordinate: blood pressure in $\mathrm{mm}$. of $\mathrm{Hg}$. The solid lines indicates curves drawn by inspection. The broken lines are curves drawn to the general empirical formula: Blood flow (c.c.) $=0.17$ (area [sq. mm.]) (blood pressure [mm. Hg.]). 
the operation is indicated in kilograms and the total amount of blood drained from the arteries during the experiment is noted in c. c.

2. An enumeration of arithmetic means obtained from this data has been carried out for the individual experiments (Table 1) and for these experiments grouped according to the cannula used (Table 2).

3. A comparison of the observed and the calculated absolute values can be made by a survey of the collected absolute curves (Fig. 7) or by inspection of the adjoining columns of observed and calculated determinations in Figures 1 and 2 .

4. The curves taken from the field graphs are collected for the purpose of comparison in Figure 7. Considering the variability of the blood pressure due to experimental error, the inspected curves from

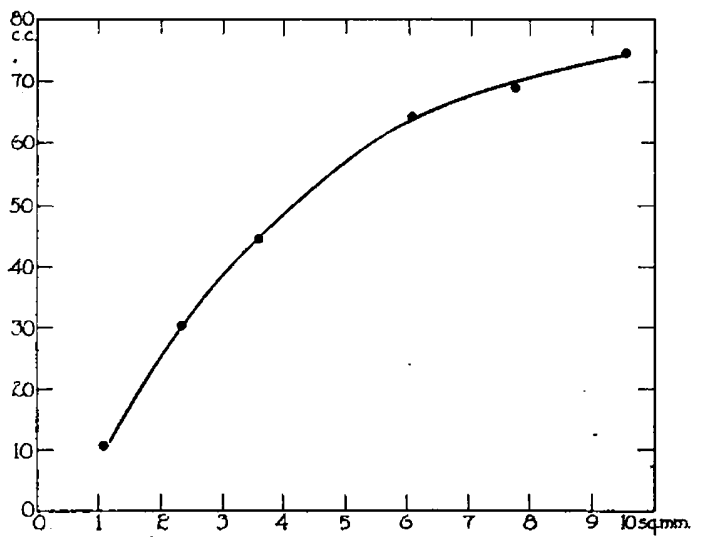

Fig. 8.-A curve to show the relationship between blood flow and the size of the cannula outlet. Abscissa: average efflux of blood in c.c. per 10 seconds of time. Ordinate: the area of the cannula outlet in sq. $\mathrm{mm}$. The solid line is a curve smoothed by inspection.

four field graphs (Fig. 1, 2, 5 and 6) fit closely the general empirical formula. The inspected and the absolute curves from Figures 3 and 4, however, show a marked deviation, especially in the intermediate values of the curve.

In Table 1 the observed absolute values of both blood flow and blood pressure can be compared to the calculated values of blood flow and blood pressure respectively.

Table 2 demonstrates the correlation of the observed blood flow and the observed blood pressure with the respective calculated blood flow and blood pressure values.

5. The significance of the relationship between blood flow and the size of the cannula outlet is portrayed in Table 2 and Figure 8 . The absolute averages of observed blood flow per ten seconds of time (Table 2) increases with the size of the cannula. In Figure 8 this 
relationship is expressed graphically. The abscissa represents the cross section area of the opening of the cannula in sq. $\mathrm{mm}$; the ordinate gives the average efflux of blood per ten seconds of time. The curve based on this absolute data is logarithmic in type. The amount of blood flowing from the cannula in a given length of time increases rapidly at first as a larger cannula is used. When cannula gage 11 is employed (which has a cross section area of 6.07 sq. mm.) the blood flow per unit of time increases at a slower rate. The efflux of blood reaches a maximum average quantity of $75 \mathrm{c}$. c. per ten seconds when a cannula, $9.512 \mathrm{sq} . \mathrm{mm}$. in area, is used.

The significance of this relationship between the flow of blood and the lumen of a cannula is not understood at the present time. It may be explained in several ways, none of them entirely satisfactory. At any rate, the general empirical formula is definitely influenced by this factor. A point is reached at which the size of the cannula makes little difference in the amount of blood flowing from an artery.

\section{ȘUMMARY}

The relationship of the blood pressure, the effux of blood from the carotid artery of a $\mathrm{dog}$, and the lumen of a cannula, the crosssection area of which ranges between 1 and 10 sq. mm., can be expressed by the general empirical formula :

Blood flow (c. c.) $=0.17$ (Area [sq. mm.]) (Blood pressure $[\mathrm{mm}$. Hg.]) 